\title{
Too bad the limbs are swollen
}

Sir,

It is quite common to hear the phrase "too bad the arms are swollen" while we are taking our routine rounds in the hospital. In all probability the nurse on duty had gone to administer an intravenous medication to a patient and found that there is phlebitis/thrombophlebitis of the limb. Now, that adds to her task of changing the line and adds to the morbidity of the patient as pain from the current swollen limb as well as from another vein being punctured and the whole scenario repeating once again. This itself might be a septic focus causing fever or spread of infection to other sites and in worse cases spread to a deep vein causing DVT or thromboembolism elsewhere. ${ }^{1}$

As long back as 1990, GD Velhal had reported 97 episodes of thrombophlebitis in 167 venepunctures, more so if the fluid infused was more than 2.5 liters and average time of occurrence being just 18 hours with the commonest organism being $P$. aeruginosa. ${ }^{2}$ Too bad the situation does not seem to have improved since. Maki DG reported a rate of 0.5 intravenous device-related bloodstream infections per 1000 intravenous device days for peripheral IV catheters and 2.7 for nontunneled, nonmedicated central venous catheters, ${ }^{3}$ going up to as high as $4.2 \%$ and $9.9 \%$ of cases in some studies. ${ }^{4,5}$

The main factor seems to be that a foreign agent is being introduced into the intravascular milieu. This is the starting point of both phlebitis and thrombophlebitis. Infection is either introduced during the placement of the cannula (bad technique) or bacteria colonize it (starting from the hub and then the lumen) before entering the intravascular space. ${ }^{6}$ While infection is always the primary suspect many chemicals starting from Cefotaxime to Bleomycin all can cause inflammation and phlebitis but are often overlooked. ${ }^{7}$ A simple changing of the offending drug, or diluting it more or changing the rate of infusion might be all that would be necessary for tackling such a problem. But too often, the members of the medical team are either ignorant or too busy to notice this.

Diagnosis is pretty straight forward and often simply clinical. ${ }^{1}$ However, there are times when we do have to investigate it with D-dimer assay and Doppler ultrasonography USGTreatment depends on etiology,
Access this article online

Website:

http://nepjol.info/index.php/AJMS

DOI: 10.3126/ajms.v10i1.21682

E-ISSN: 2091-0576

P-ISSN: $2467-9100$

extent and symptoms. ${ }^{8}$ Duplex USG gives an accurate extent of the disease and administration of a more rational therapy. ${ }^{8}$ But this just adds to the cost of care and in many locations worldwide (especially in developing countries) it is not available. So we are back to basics, diagnose it clinically. Then comes the even more difficult part. How to manage? India is a land of diversity and no wonder, the lines of management are just as diverse. We find clinicians advising elevation of the limb (trying to decrease the swelling with the help of gravity), flushing the cannula with heparin trying to regain patency of the lumen (and unknowingly dislodge a septic focus or a clot to cause a more serious condition), wrapping the limb in a paste of magnesium sulphate (trying to extract fluid out of the oedematous area by osmosis), application of Heparin jelly to the affected area (hoping that it would get absorbed through the skin and imbibe into the blocked vein), application of heat to the area (might work to some extent), the number of adventures and misadventures remain innumerable. No definite structured research could be found regarding these, including 2 Cochrane database of systematic review articles and such local therapies had been excluded as there is no adequate studies on them., ${ }^{9,10}$

So can we start treating superficial vein phlebitis and thrombophlebitis in a more rational way? Removing the cannula and sending it for culture sensitivity would be a rationale step as that would remove a foreign/irritating agent as well as a possible harbor of infection. Starting an analgesic is would be common sense, especially an NSAID (non-steroidal anti-inflammatory drug) if not otherwise contraindicated. After all, there is local inflammation and the patient would obviously be in pain and hence there would be symptomatic relief. Antibiotics are not routinely indicated unless septic or suppurative thrombophlebitis are being considered, in which case MRSA (Methicillin resistant Staph aureus) should be covered in addition to 
routine skin flora. If these are suspected, the condition is quite serious and immediate and complete excision of all of the involved veins is indicated in addition to proper antibiotic and anticoagulant therapy. ${ }^{8}$ In some cases, such major interventions might not be necessary and mere aspiration of the contents of the venous lumenwith a wide bore needle and sending the aspirate for culture sensitivity might be adequate. ${ }^{8}$ According to ACCP 2012 "superficial thrombophlebitis of $\geq 5 \mathrm{~cm}$ in length is to be treated with a mid-treatment dose of LMWH (e.g. enoxaparin $60 \mathrm{mg}$ once daily or with fondaparinux $2.5 \mathrm{mg}$ ) once daily for 6 weeks". ${ }^{11}$ Topically applied anticoagulant cream may accelerate the healing of a superficial venous thrombus ${ }^{1}$ but concrete evidence is lacking till date. However, only mild superficial thrombophlebitis associated with an intravenous cannula is usually not treated with systemic anticoagulants. ${ }^{1}$ First-line treatment consists of removal of the cannula and topical treatment and/or a NSAID if needed as the inflammation is expected to recover in 2 to 6 weeks, however, the obstructed vein may occasionally remain symptomatic for months. ${ }^{1}$

\section{Kaushik Ghosh ${ }^{1}$, Ambarish Bhattacharya ${ }^{2}$, Muhammad Imran Ahmad Qureshi ${ }^{3}$}

${ }^{1}$ Assistant Professor, Department of Medicine, Murshidabad Medical College, West Bengal, India, ${ }^{2}$ Visiting Consultant, Charnock Hospital, Kolkata, West Bengal, India, ${ }^{3}$ Consultant, Department of Acute Medicine, Worcestershire Acute Hospitals NHS Trust, United Kingdom

Address for Correspondence: Dr Kaushik Ghosh, Assistant Professor, Department of Medicine, Murshidabad Medical College, Berhampore, West Bengal
E-mail: drkaushikghosh@gmail.com. Tel No: +919547901343

\section{REFERENCES}

1. Superficial venous thrombosis. EBM guidelines. 12.12.2013

2. Velhal GD, Bichile SK, Mehta PJ and Joshi VR. Study of iatrogenic thrombophlebitis. J Assoc Physicians India 1990; 38(3):215-217.

3. Maki DG, Kluger DM and Crnich CJ. The risk of bloodstream infection in adults with different intravascular devices: a systematic review of 200 published prospective studies. Mayo Clin Proc 2006; 81(9):1159-1171.

4. Pruitt BA, McManus WF, Kim SH and Treat RC. Diagnosis and treatment of cannula-related intravenous sepsis in burn patients. Ann Surg 1980; 191(5):546-554.

5. Richet H, Hubert B, Nitemberg G, Andremont A, BuuHoi A, Ourbak P, et al. Prospective multicenter study of vascularcatheter-related complications and risk factors for positive central-catheter cultures in intensive care unit patients. J Clin Microbiol 1990; 28(11):2520-2525.

6. Khardori $\mathrm{N}$ and Yassien M. Biofilms in device-related infections. J Ind Microbiol 1995; 15(3):141-147.

7. http://www.rightdiagnosis.com/p/phlebitis/medic.htm

8. Adam J Rosh. Superficial Thrombophlebitis Treatment \& Management. Updated: Jul 12, 2016. http://emedicine. medscape.com/article/463256-treatment\#showall.

9. Di Nisio $M$, Wichers $I M$ and Middeldorp S. Treatment for superficial thrombophlebitis of the leg. Cochrane Database Syst Rev 2007; CD004982.

10. Di Nisio M, Wichers IM, Middeldorp S. Treatment for superficial thrombophlebitis of the leg. Cochrane Database Syst Rev 2013; 4:CD004982.

11. Kearon C, Akl EA, Comerota AJ, Prandoni P, Bounameaux H, Goldhaber SZ, et al. Antithrombotic therapy for VTE disease: Antithrombotic Therapy and Prevention of Thrombosis, 9 $9^{\text {th }}$ ed: American College of Chest Physicians Evidence-Based Clinical Practice Guidelines. Chest 2012; 141(2 Suppl):e419S-94S.

\footnotetext{
Authors Contribution:

KG, AB and MIAQ- Conceptualized study, literature search, statistically analyzed and interpreted, prepared first draft of manuscript and critical revision of the manuscript.

Orcid ID:

Dr. Kaushik Ghosh - (i) http://orcid.org/0000-0002-2972-6441

Source of Support: Nil, Conflict of Interest: None
} 